\title{
Multiple equilibria in tidal eco-geomorphology
}

\author{
M. Marani, A. D’Alpaos, S. Lanzoni, L. Carniello \& A. Rinaldo \\ Department IMAGE, University of Padova, Padova, Italy
}

\begin{abstract}
The dynamics of estuaries and lagoons are the result of complex feedbacks between coupled biotic (e.g. linked to halophytic vegetation and microphytobenthos) and abiotic processes (chiefly sediment erosion and deposition, hydrodynamics, eustatism and sea-level change). In contrast, our understanding of their dynamics has so far evolved within separate disciplines, e.g. concerned with the morphological evolution of tidal flats, marshes and channels or with specific compartments of tidal ecosystems, such as marsh vegetation or microphytobenthos. Here we introduce an eco-geomorphological model for the time evolution of the elevation of a tidal platform regularly inundated by the tide. The model, based on the sediment continuity equation, includes the effects of vegetation and microphytobenthos on sediment erosion and deposition. A variable set of stable and unstable equilibria emerges, depending upon suspended sediment availability, type of vegetation, disturbance of the benthic biofilm, and rate of sea level change. We show that switches between stable states may occur, providing explanations for the observed response of real tidal systems to disturbances and changes in external forcings.
\end{abstract}

\section{INTRODUCTION}

Lagoons and estuaries host typical tidal ecosystems and landforms. They are sites characterized by extremely high biodiversity and rates of primary productivity, and quite important socio-economic activities worldwide, such that their ecosystem services is acknowledged as fundamental (Mitsch \& Gosselink 2000, Cronk \& Fennessy 2001). The ecological and morphological components of the embedded transition zones between marine and terrestrial ecosystems are dynamically coupled by complex interactions between intertidal vegetation (Cronk \& Fennessy 2001, Silvestri et al. 2005, Marani et al. 2006a, b), benthic microbial assemblages (Paterson 1989), erosion and deposition processes (D'Alpaos et al. 2005, Day et al. 1999, Kirwan and Murray, in press, Fagherazzi et al. 2006, Allen 1997), hydrodynamics (Rinaldo et al. 1999, Marani et al. 2004), eustatism and/or relative sea-level change (Allen 1997). However, our understanding of the coupled eco-geomorphic evolution of tidal systems is still very limited and has so far evolved within separate disciplines, like e.g. those concerned with the morphological evolution of tidal flats, marshes and channels (D'Alpaos et al. 2005, Fagherazzi et al. 2006, Allen, 1997) or with specific compartments of tidal ecosystems, such as halophytic vegetation or microphytobenthos (Mitsch \& Gosselink 2000, Cronk \& Fennessy 2001, Paterson 1989). As a result, we still lack a comprehensive and predictive theory of the joint evolution of tidal landforms and biota.

Here we introduce a fully coupled eco-geomorphic model for the elevation of a tidal platform regularly inundated by the tide and possibly colonized by benthic assemblages and intertidal vegetation. This approach allows us to study the nature of the equilibrium states of the system as jointly determined by physical and biological processes.

\section{MODEL STRUCTURE}

The time evolution of the spatially-averaged elevation of a tidal platform, $z(t)$ (measured with respect to mean sea level), is described by mass balance (Marani et al., submitted; Figure 1A):

$$
\begin{aligned}
& \frac{d z}{d t}=Q_{S}(z, B)+Q_{T}(z, B)+Q_{O}(B)- \\
& -E[z, B, M P B(z)]-R=F(z, B)-R
\end{aligned}
$$

In eq. (1): $B$ is the annually-averaged above-ground halophytic vegetation biomass. $M P B(z)$ indicates the functional dependence on microphytobenthos, controlled by elevation. $R$ is the rate of relative sea level (RSL) change, i.e. sea level variations plus local subsidence. $Q_{S}(z, B)=1 / T \cdot \int_{T} C(z, B, t) w_{s} / \rho_{S} d t$ 

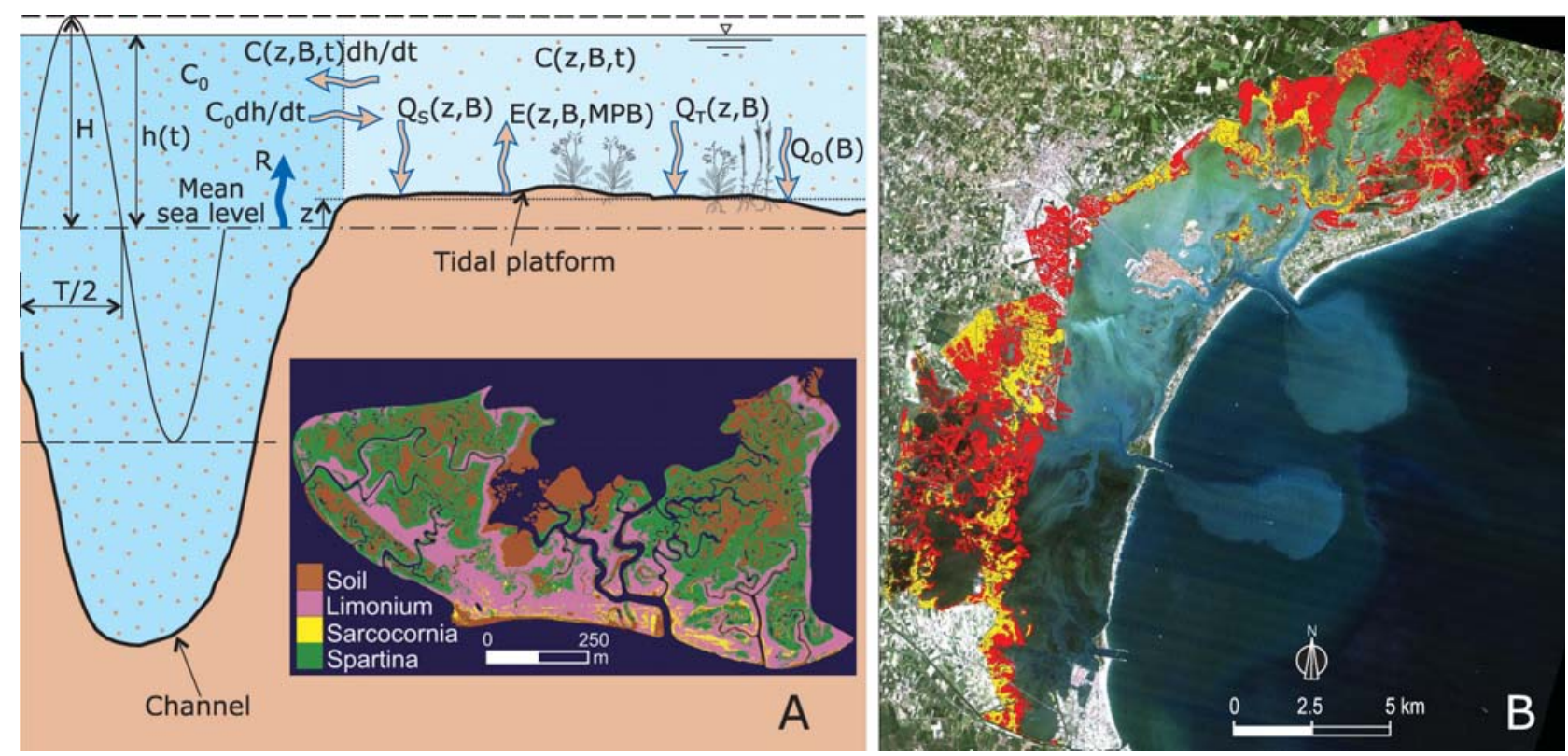

Figure 1. (A) Sketch of sediment fluxes at the surface of a tidal platform and sediment exchanges with its surroundings as accounted by equation (1). Landscape-forming tides are assumed to be sinusoidal with half-amplitude $\mathrm{H}$ and period T. The elevation $z(t)$ of the platform is computed with respect to the local mean sea level. The remotely-sensed map in the inset shows the presence of multiple halophytic species within a marsh in the Venice lagoon (Belluco et al. 2006); (B) image of the Venice lagoon from a Landsat ETM+ scene acquired during ebb (Courtesy of Ministero delle Infrastructure e dei Trasporti Magistrato alle Acque di Venezia - through its Concessionario Consorzio Venezia Nuova). Two large sediment plumes are clearly visible: The jetties at the inlets cause an asymmetry in the flow such that only a small fraction of the sediments ejected during ebb re-enters the lagoon during flood. Red, marshes disappeared since 1811. Yellow, the surviving marshes.

(Figure 2A) is the average sediment settling flux over a tidal cycle, which chiefly depends from the instantaneous sediment concentration, $C(z, B, t)$, in turn determined by solving a sediment balance equation for the water column forced by the average sediment concentration in lagoonal waters, $C_{0}$, resulting from past resuspension events and possible (e.g. fluvial) sediment inputs (Krone 1987, Marani et al. submitted). $w_{s}$ is the settling velocity (computed for a typical $\left.d_{50}=50 \mu \mathrm{m}: w_{s}=0.2 \mathrm{~mm} / \mathrm{s}\right) \rho_{s}$ is the sediment density (here $\rho_{s}=2650 \mathrm{~kg} / \mathrm{m}^{3}$ ). $Q_{T}(z, B)=1 / T \int_{T} C(z, B, t) \alpha B^{\beta} / \rho_{s} d t$ (Figure 2B) is the average over a tidal cycle of the deposition rate due to trapping of suspended sediment by the canopy ( $\alpha$ and $\beta$ are parameters which account for vegetation and flow characteristics (Mudd et al. 2004). $Q_{O}(B)=\gamma \cdot B$ (Figure 2C) is the production of organic soil due to vegetation (combining above- and below-ground biomass production, Randerson 1979). $E(z, B, M P B)=1 / \rho_{s}$. $m \cdot \overline{\left(\tau-\tau_{c}\right)} / \tau_{c}$ (Figure 2D)is the tidally-averaged erosion rate, mainly due to wind-induced waves. The erosion rate depends, through the erosion coefficient $m$, on sediment type and structure, an effective bottom shear stress ( $\tau$, a complex function of water depth, wind velocity, fetch (Carniello et al. 2005), and vegetation presence, which efficiently dissipates wind waves (Möller et al. 1999), and a threshold shear stress for erosion, $\tau_{c}$, strongly dependent on stabilizing polimeric biofilms produced by benthic microbes (e.g., Paterson 1989, Amos et al. 1998). Because microphytobenthos growth is light-limited, we assume a sharp increase in erosion thresholds when the platform elevation yields sufficient incoming solar irradiance for microbial photosynthetic activity to occur (MacIntyre et al. 1996, Marani et al. 2007).

Vegetation dynamics is described through a logistic model (Levins, 1969), in which biomass is expressed as the product of vegetation fractional cover, $p$, and the carrying capacity of the system, $d$ (maximum biomass per unit area), i.e. $B=p d$. The rate of biomass change is given by:

$\frac{d B}{d t}=\frac{r(z) B}{d}(d-B)-m(z) B=G(z, B)$

where: $r(z)$ and $m(z)$ are elevation-dependent reproduction and mortality rates respectively. Such rates reflect the physiological responses of halophytic species to the controlling environmental conditions, chiefly soil water saturation locally surrogated by elevation (Silvestri et al. 2005, Marani et al. 2006c, Marani et al., submitted).We compare here two typical and contrasting situations. The first is a Spartina spp.-dominated case (characteristic of many NorthAmerican and U.K. sites), in which biomass is a decreasing function of elevation between mean sea level $(z=0)$ and mean high water level $(z=H)$, 

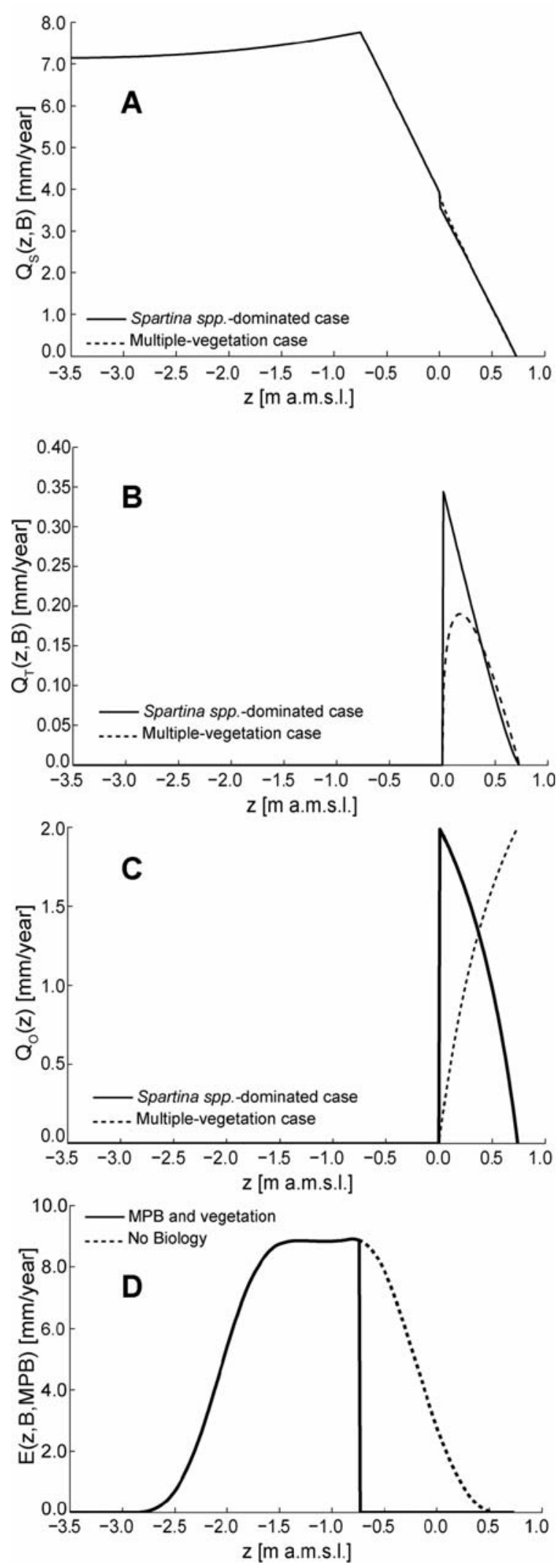

Figure 2. (A) Sediment settling flux, $Q_{S}(z, B(z))$, obtained by assuming the equilibrium biomass $B(z)$ resulting from posing $\mathrm{dB} / \mathrm{dt}=0$ in eq. (2); (B) Trapping of sediment by the canopy, $Q_{T}(z, B(z))$; (C) organogenic sediment flux $Q_{O}(B(z))$; (D) Erosion rate, $E(z, B(z), M P B(z))$, with and without biostabilization. reflecting the adaptation of Spartina to hypoxic conditions (Morris et al., 2002). The second is a multiplevegetation case, typical of mediterranean tidal environments, such as the Venice lagoon (Figure 1A), or of sites in northern continental Europe. It is characterized by biomass increasing with soil elevation due to the competition among species adapted to progressively more aerated conditions (Silvestri et al. 2005, Marani et al., 2004). To describe the physiological adaptation of Spartina to waterlogged conditions, we use a reproduction rate which linearly decreases with elevation, while the mortality rate is assumed to increase linearly with $z$. We also assume each plant to produce at most one daughter plant per year in the most favourable conditions, i.e. $r(0)=1$ year $^{-1}$, while $m(0)=0$ year $^{-1}$. In order for the steady-state biomass at $z=H$ to be equal to zero, as observed (Morris et al. 2002), we take $r(H)=m(H)=0.5$ year $^{-1}$. Similarly, the multiple-species case is modelled by assuming $r(H)=1$ year $^{-1}$ and $m(H)=0$ year $^{-1}$, whereas $r(0)=m(0)=0.5$ year $^{-1}$ in order for the steady-state biomass to be zero at $z=0$, according to observations (Silvestri et al. 2005, Marani et al. 2004).

\section{RESULTS AND DISCUSSION}

The Equations (1) and (2) describe the time evolution of a nonlinear dynamical system which can exhibit stable and/or unstable equilibrium states (Strogatz 1994), whose study requires specification of parameter values characterizing the particular environment of interest. Here we analyze the case of landforms within the Venice lagoon (Figure 1B) whose fate is of great concern. We first consider a 20th-century scenario, which assumes the characteristic rate of sea-level rise of $2 \mathrm{~mm} /$ year (IPCC 2001, Carbognin et al. 2004), and a local subsidence of $1.5 \mathrm{~mm} /$ year (Carbognin et al. 2004), for a total $R=3.5 \mathrm{~mm} /$ year. The tidal excursion is $2 H=1.48 \mathrm{~m}$, the tidal period is $T=12$ hours. We also take $C_{0}=20 \mathrm{~g} / \mathrm{m}^{3}$ as a characteristic suspended sediment concentration, based on long series of water turbidity observations (Marani et al., submitted).

The dynamics of the system may be represented in phase space (Figure 3A) which is two-dimensional when $z \geq 0$, and becomes one-dimensional for $z<0$ (because, in this case, $B=0$ ). In the case of the Venice lagoon two stable equilibria are possible: A sub-tidal (i.e. permanently submerged) platform and a vegetated marsh. The arrows in phase space represent the time evolution of the system out of equilibrium and highlight the stable nature of its equilibria (solid circles in Figure 3A). The stability of the equilibrium for $B>0$ is controlled by the eigenvalues of the Jacobian matrix obtained from equations (1) and (2). In the case at hand the values of the determinant and of the trace of the Jacobian (inset in Figure 3A) are such that both eigenvalues are real and negative, and thus the marsh 

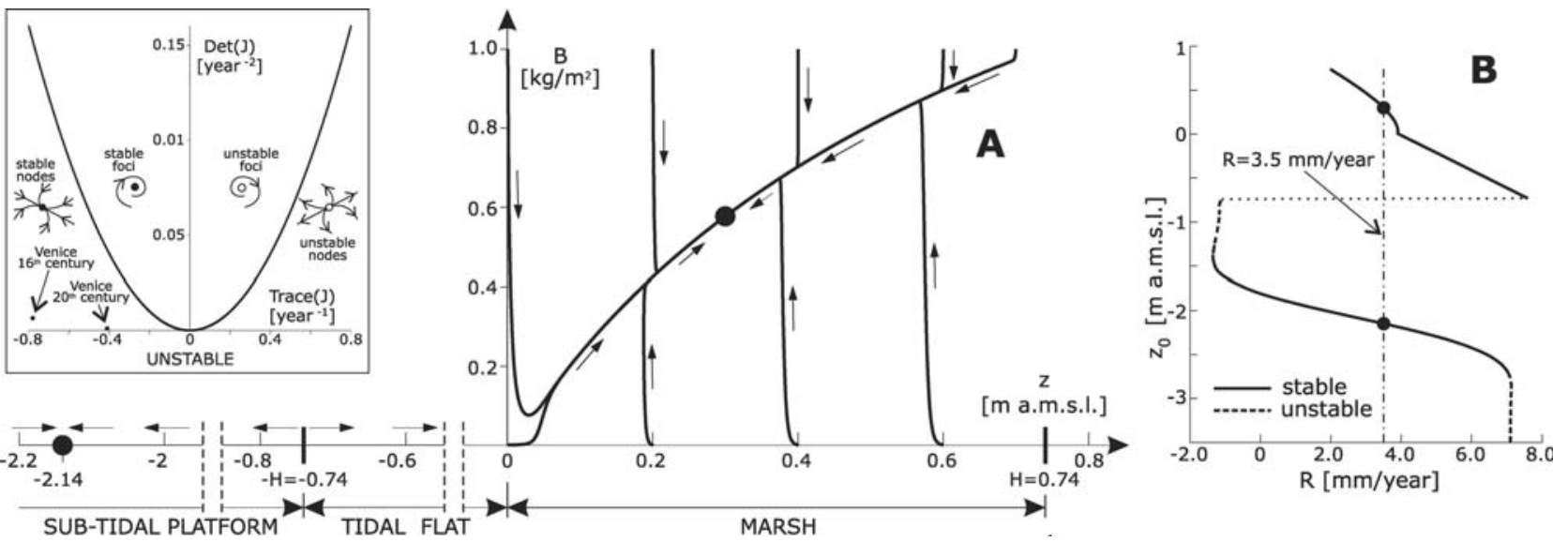

Figure 3. (A) Phase portrait of the dynamics of a Venice-like tidal system in the 20th-century scenario. When $\mathrm{z}<0$ biomass is $\mathrm{B}=0$ and the phase space becomes one-dimensional. A stable equilibrium corresponds to a 'sub-tidal platform', i.e. an unvegetated and permanently submerged platform not colonized by microphytobenthos, with $\mathrm{z}=-2.14 \mathrm{~m}$ a.m.s.1.. A second stable state corresponds to a vegetated marsh with $\mathrm{z}=0.30 \mathrm{~m}$ a.m.s.l.. Inset: The determinant and the trace of the Jacobian of the system of equations (1) and (2) determine the nature of the equilibrium states. A stable node in the case of the marsh equilibrium. (B) Bifurcation diagram showing the ranges of $\mathrm{R}$ for which stable and/or unstable states exist.

equilibrium state is a stable node (Strogatz 1994). The nearly vertical trajectories for $z>0$ in Figure 3A show that biomass adjustments are quasi-instantaneous with respect to elevation changes.

The bifurcation diagram (Figure 3B) shows the alternative equilibria available to the system as a function of the rate of RSL change. The 20th-century value $R=3.5 \mathrm{~mm} /$ year corresponds to two stable equilibria, as discussed above. Higher values of $R$ may lead to a transition from a marsh to a tidal-flat equilibrium $(R>3.9 \mathrm{~mm} /$ year $)$, while rates greater than $R=7.7 \mathrm{~mm} /$ year cause all intertidal equilibria to vanish. Similarly, the sub-tidal equilibrium state becomes progressively deeper for increasing values of $\mathrm{R}$ and disappears for $R>7.2 \mathrm{~mm} / \mathrm{year}$. For values $R<2.0 \mathrm{~mm} /$ year a marsh equilibrium is no longer possible (and marshes are transformed into terrestrial environments), whereas the sub-tidal equilibrium vanishes for $R<-1.4 \mathrm{~mm} /$ year (sea regression).

Because of the instantaneous adjustment of biomass to elevation changes, yielding the steady-state biomass $B(z)$, equilibrium states can also be characterized by studying $F(z, B(z))$ vs. $z(15)$. Such an analysis for a Spartina-dominated system (Figure 4A-C) shows that no equilibrium state exists for $R<-1.4 \mathrm{~mm} /$ year (Figure $4 \mathrm{~A}$ ). In the case of a relatively fast sea regression, the tidal environment is transformed into a terrestrial one. For a RSL rise typical of the 20th century, two stable equilibria are possible, identified by the condition $F(z, B(z))-R=0$ (solid circles), one associated to a sub-tidal platform and the other to a vegetated marsh (Figure 4B). In both cases small perturbations in $z$ imposed to the system are dissipated by its subsequent evolution and the original equilibrium states are eventually recovered, thus marking their stable nature. Three stable equilibria can coexist for $3.9<R<5.9 \mathrm{~mm} /$ year (Figure 4C). Interestingly, a stable tidal flat equilibrium is added to those of the previous case. For $5.9<R<7.2 \mathrm{~mm} /$ year the subtidal-platform and the tidal-flat equilibria coexist.

When $7.2<R<7.7 \mathrm{~mm} /$ year the sub-tidal equilibrium vanishes, while also the tidal-flat equilibrium state disappears for $R>7.7 \mathrm{~mm} /$ year: Values of $R$ exceeding this threshold will thus inevitably lead to evolution towards a marine environment. In the multiple-species case (Figure 4D-F) a vegetated marsh state exists for $2.0<R<3.9 \mathrm{~mm} /$ year, compared to $0<R<5.9 \mathrm{~mm} /$ year for Spartina-dominated cases. This suggests that marshes in which vegetation biomass increases with elevation (e.g. the Venicelike case) are less resilient (all other conditions being equal) to variable rates of RSL change with respect to marshes in which biomass is a decreasing function of $z$ (e.g. Spartina-dominated case). For values of $R$ beyond the upper limit, salt-marsh accretion is unable to balance RSL rise and, as a consequence, the system evolves towards a stable tidal flat. These results indicate that coastal marshes may not survive climatic changes in the next century as global rates of sea level rise are predicted in the range $0.8-8.5 \mathrm{~mm} /$ year (IPCC, 2001).

The geomorphic role of biological processes is best appreciated by considering the equilibrium states in the hypothetical situation in which microphytobenthos and vegetation are not allowed to develop (Figure 4A-F, dashed lines). In this case a tidal flat equilibrium is possible only for narrow ranges of rates of RSL rise $(-1.5<R<-1.1 \mathrm{~mm} /$ year and $0<R<1.8 \mathrm{~mm} /$ year) and the basin of attraction of stable equilibria lying within the tidal range is much 

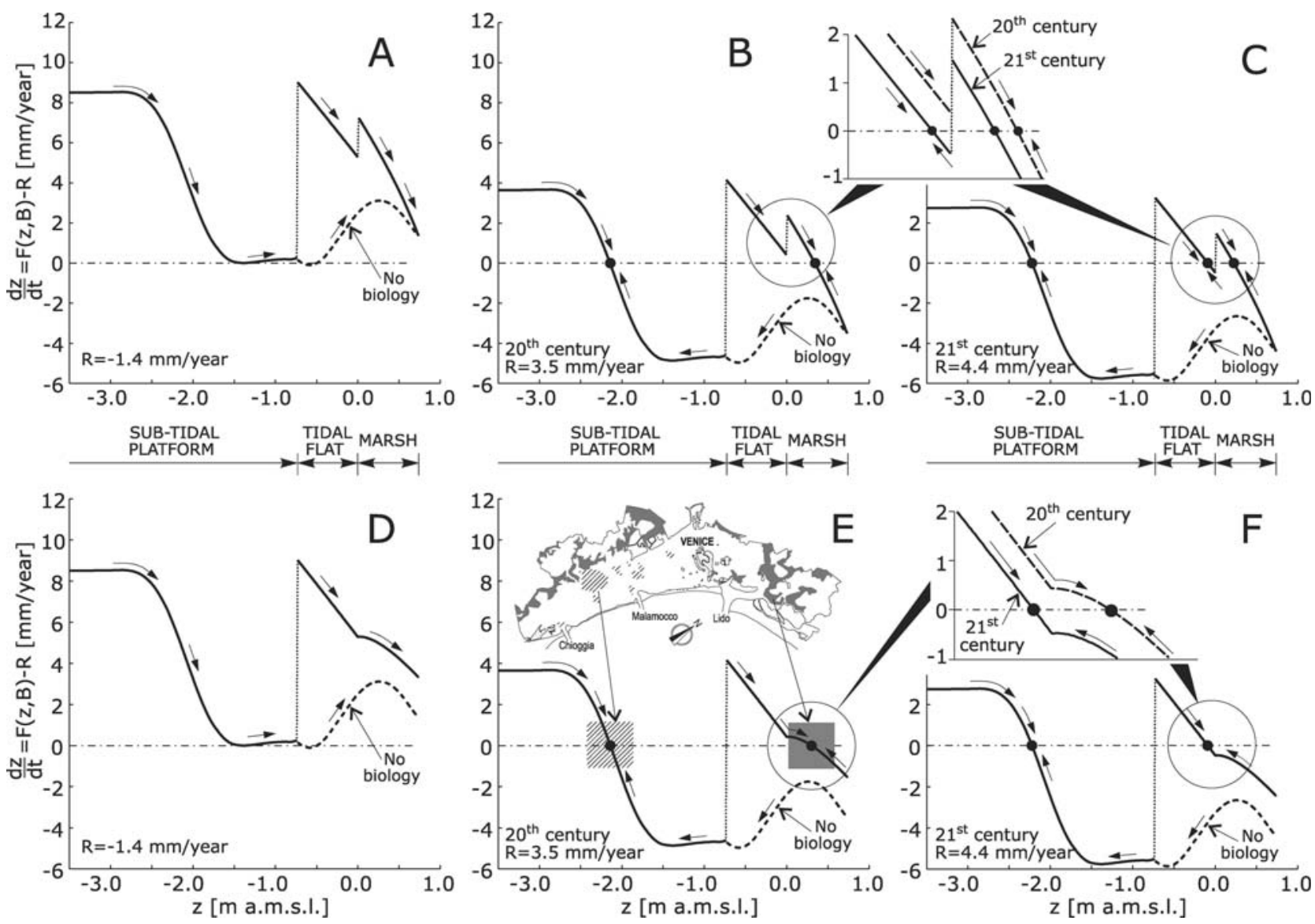

Figure 4. Stable states under different vegetation and rates of RSL scenarios. 20th-century climatic conditions yield two stable equilibria in the Spartina-dominated and in the multiple-vegetation scenarios (panels B and E). In the former case, a third 'shallow' tidal-flat equilibrium is also possible for higher rates of RSL rise (e.g. panel C, for $\mathrm{R}=4.4 \mathrm{~mm} / \mathrm{year}$, the central value in the forecast interval reported by IPCC (26)). The hypothetic case in which no biological activity is present (i.e. no microphytobenthos and no vegetation, dashed curves in all panels) illustrates the strong biotic control on the number and type of equilibria.

wider $(-0.74<z<0.74 \mathrm{~m}$ a.m.s.l) than in abiotic cases $(0.27<z<0.74 \mathrm{~m}$ a.m.s.l). The abiotic scenario also provides insight into the dynamics of the system in the case of a sediment poor in polimeric biofilms owing to: reduced biological activity; external disturbances (such as clam harvesting mechanically disrupting the surficial biofilm (Paterson 1989); or bioturbation, e.g. due to grazing or invertebrates (Daborn et al. 1993). The disruption of the microbial biofilm radically changes the evolution of the system (compare the corresponding dashed and solid lines in Figure 4A-F) leading to the demolition of tidal flats, which would be accreting in the presence of microphytobenthos.

A sub-tidal platform is the only accessible stable equilibrium under the new conditions. Therefore the systematic destruction of the stabilizing polimeric biofilm produces a progressive erosion of tidal flats. Because benthic assemblages cannot colonize the surface when incoming solar radiation is insufficient, this trend becomes irreversible below $z=-H$. We thus conclude that biological controls largely determine the existence of stable intertidal structures and the transition among them. The possible appearance (and vanishing) of stable equilibrium states can be shown to generate hysteretic behaviours during cycles of RSL acceleration/deceleration (inset in Figure 4C Also see Marani et al., submitted).

We already noted that two alternative stable states coexist in the 20th-century scenario for the Venice lagoon (Figure 3 and 4E). The sub-tidal platform stable elevation is $z \sim-2.14 \mathrm{~m}$ a.m.s.l., whereas the vegetated marsh stabilizes at $z \sim 0.30 \mathrm{~m}$ a.m.s.l. (coherently with observations (Day et al. 1999, Marani et al. 2004, Silvestri et al. 2005). Confirmations of our predictions can be sought from the known evolution of the Venice lagoon over past centuries in response to the Anthropocene, in particular the strong erosional trend that caused a major reduction of salt-marsh areas during the 20th century (Figure 1B). Comparisons of the configurations at the beginning of 1900 and the current one show that, in response to these changes, the typical elevation of unvegetated platforms (initially approximately equal to $-0.5 \mathrm{~m}$ a.m.s.1.) has been 


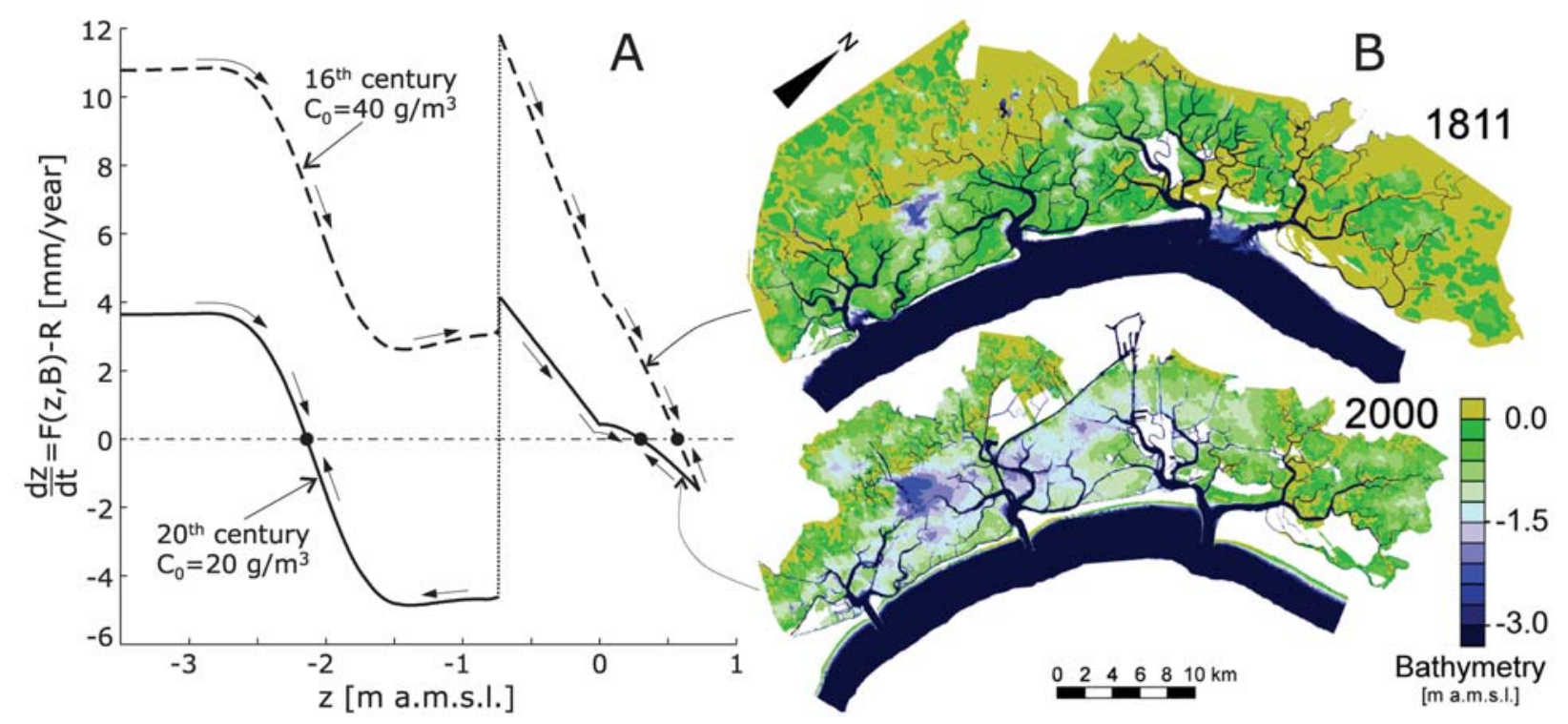

Figure 5. At the end of the sediment-poor 20th-century wide sub-tidal areas coexist with a moderate presence of intertidal marshes in the Venice lagoon, as predicted by the model (solid line in panel A and lower image in panel B). On the contrary, the sediment-rich 16th-18th century period led to a configuration dominated by marshes with very limited sub-tidal platforms (dashed line in panel A and upper image in panel B). Panel B adapted from D’Alpaos (2004).

steadily decreasing. However, no increase in depth beyond $z=-2.4 \mathrm{~m}$ a.m.s.l. has been observed (Defina et al., in press). This suggests that indeed the average lagoon depth is deepening but that the maximum depth of a sub-tidal platform is bounded from below by a stable equilibrium for $z \cong-2.4 \mathrm{~m}$ a.m.s.l., quite close to the value predicted by the model.

The analysis of the equilibrium states corresponding to different scenarios of sediment availability can elucidate trends and mechanisms characterizing different phases in the life of a tidal system. Again we consider the much-documented evolution of the Venice lagoon. The largely positive sediment balance of the system typical of pre-16th century conditions is represented here by assuming $C_{0}=40 \mathrm{~g} / \mathrm{m}^{3}$, compared to $C_{0}=20 \mathrm{~g} / \mathrm{m}^{3}$ characteristic of the 20 th century case (Figure 5). In the pre-16th century conditions the settling flux was such that deposition dominated over erosion. An equilibrium could be found only for high elevations, when sediment settling is reduced owing to a diminished submergence period, and vegetation has encroached the marsh. The lagoon, under such conditions, tends toward a configuration dominated by high marshes, in which tidal flats and sub-tidal platforms disappear. Various accounts (Marani et al., submitted) and 19th Centuries bathymetries (D'Alpaos 2004) agree. In 1811 the area covered by marshes amounted to about $150 \mathrm{~km}^{2}$, compared to a total lagoon area of $580 \mathrm{~km}^{2}$. In 2003, marshes extended for about $50 \mathrm{~km}^{2}$ while the total lagoon area was $480 \mathrm{~km}^{2}$ (reduced with respect to 1811 mainly because of land reclamation). Marsh surfaces were thus reduced from about $26 \%$ of the total lagoon area to just $10 \%$.

\section{CONCLUSIONS}

Our model provides a concise description of the dynamics of tidal landforms and environments which, in spite of its structural simplicity, yields a surprisingly rich variety of system responses to changes in forcings. We suggest that the complexity observed in tidal geomorphological patterns may indeed arise from the mutual influence of biotic and abiotic components, and that the fate of landforms and of their possible geomorphological restoration can indeed be predicted, thus pointing at the importance of eco-morphodynamic approaches for conservation studies.

\section{ACKNOWLEDGEMENTS}

This work was supported by the PRIN 2006 project 'Modelli dell'evoluzione eco-morfologica di bassifondi e barene lagunari', the PRIN 2006 project 'Fenomeni di trasporto nel ciclo idrologico', the University of Padova research project 'Telerilevamento della zonazione e della biodiversità della vegetazione sulle barene della laguna di Venezia', and the VECTOR-FISR 2002 project, CLIVEN research line 5. M.M. is grateful to dott. Giancarlo Biotto for performing the GIS analyses necessary to produce Fig. 1B.

\section{REFERENCES}

Allen, J. R. L. 1997. Salt-marsh growth and stratification: a numerical model with special reference to the Severn Estuary, southwest Britain. Mar. Geol. 95: 77-96. 
Amos, C. L., Brylinsky, M., Sutherland, T. F., O’Brien, D., Lee, S., Cramp, A. 1998. The stability of a mudflat in the Humber estuary, South Yorkshire, UK, in Black, K.S., Paterson, D.M., Cramp, A. (Eds.) Sedimentary Processes in the Intertidal Zone, Geol. Soc. London Spec. Publ., 139, $25-43$.

Belluco, E., Camuffo, M., Ferrari, S., Modenese, L., Silvestri, S., Marani, A., Marani, M. 2006. Mapping saltmarsh vegetation by multispectral and hyperspectral remote sensing, Remote Sensing of Env., 105: 54-67, doi:10.1016/j.rse.2006.06.06.

Carbognin, L., Teatini, P., Tosi L. 2004. Eustacy and land subsidence in the Venice Lagoon at the beginning of the new millennium. J. Marine Syst. 51: 345-353.

Carniello, L., Defina, A., Fagherazzi, S., D’Alpaos, L. 2005. A combined wind wave-tidal model for the Venice Lagoon, Italy, J. Geophys. Res. 110, F04007.

Cronk, J. K. \& Fennessy, M. S. 2001. Wetland Plants: Biology and Ecology Lewis Publishers, Boca Raton, FL.

Daborn, G.R., Amos, C.L., Brylinsky, M., Christian, H. 1993. An ecological cascade effect: Migratory birds affect stability of intertidal sediments, Limnol. Oceanogr., 34, 225-231.

D’Alpaos, A., Lanzoni, S., Marani, M., Fagherazzi, S., Rinaldo, A. 2005. Tidal network ontogeny: channel initation and early development. J. Geophys. Res. 110, F02001, doi:10.1029/2004JF000182.

D’Alpaos, A., Lanzoni, S., Marani, M., Rinaldo, A. 2007. Landscape evolution in tidal embayments: Modeling the interplay of erosion, sedimentation and vegetation dynamics, J. Geophys. Res., 112, doi:10.1029/ 2006JF000537.

D'Alpaos, L. 2004. Conoscere il comportamento idrodinamico della laguna del passato per progettare la laguna del futuro, in Atti, Istituto Veneto di Scienze, Lettere ed Arti, 162, pp 377-422, Venice.

Day, J. W., Rybczyk, J., Scarton, F., Rismondo, A., Are, D., Cecconi, G. 1999. Site accretionary dynamics, sea-level rise and the survival of wetlands in Venice lagoon: A field and modelling approach, Estuarine Coastal Shelf Sci. 49: 607-628.

Defina, A., Carniello, L., D’Alpaos, L., Fagherazzi, S. 2007. Spatial organization of shallow tidal lagoons in tidal flats and salt marshes, J. Geophys. Res., doi:10.1029/2006JF000550

Dorigo, W. 1938. Venezia Origini, Electa, Venezia.

Fagherazzi, S., Carniello, L., D’Alpaos, L., Defina, A. 2006. Critical bifurcation of shallow microtidal landforms in tidal flats and salt marshes, Proc. Natl. Acad. Sci. USA 103: 8337-8341.

IPCC, Climate change 2001. The scientific basis. http:// www.grida.no/climate/ipcc_tar/wg1/index.htm.

Kirwan, M. L., Murray A. B. 2007. A coupled geomorphic and ecological model of tidal marsh evolution, $P N A S$, in press.

Krone, R.B. 1987. A method for simulating historic marsh elevations. In Kraus, N. C. (Ed.) Coastal Sediments '87, American Society of Civil Engineers, New York, pp. 316-323.

Levins, R. 1969. Some demographic and genetic consequences of environmental heterogeneity for biological control, Bulletin of the Entomological Society of America, 15: 237-240.
Marani, M., Lanzoni, S., Belluco, E., D’Alpaos, A., Defina, A., Rinaldo, A. 2003. On the drainage density of tidal networks, Water Resources Research 39 (2), 105-113.

Marani, M., Lanzoni, S., Silvestri, S., Rinaldo, A. 2004. Tidal landforms, patterns of halophytic vegetation and the fate of the lagoon of Venice, J. Marine Syst. 51: 191-210.

Marani M., Belluco, E., Ferrari, S., Silvestri, S., D’Alpaos, A., Lanzoni, S., Feola, A., Rinaldo, A. 2006. Analysis, synthesis and modelling of high-resolution observations of salt-marsh ecogeomorphological patterns in the Venice lagoon, Estuarine Coastal Shelf Sci. 69: 414-426.

Marani, M., Silvestri, S., Belluco, E., Ursino, N., Comerlati, A., Tosatto, O., Putti, M. 2006. Spatial organization and ecohydrological interactions in oxygen-limited vegetation ecosystems, Water Resour. Res., 42, W07S06, doi:10.1029/2005WR004582.

Marani, M., Zillio, T., Belluco, E., Silvestri, S., Maritan, A., 2006. Non-neutral vegetation dynamics. PLoS ONE 1(1).

Marani, M., D'Alpaos, A., Lanzoni, S., Carniello, L., Rinaldo, A. Biologically-controlled multiple equilibria of tidal ladnforms and the fate of the Venice Lagoon, submitted.

MacIntyre, H. L., Geiger, R. J., Miller, D. C. 1996. Microphytobenthos: The Ecological Role of the "Secret Garden" of Unvegetated, Shallow-Water Marine Habitats. 1. Distribution, Abundance and Primary Production, Estuaries, 19(2A): 186-201.

Mitsch, W.J., Gosselink, J. G. Wetlands, Wiley, New York, ed. 3,2000 .

Möller, I., Spencer, T., French, J. R., Leggett, D. J., Dixon, M. 1999. Wave Transformation Over Salt Marshes: A Field and Numerical Modelling Study from North Norfolk, England. Estuarine, Coastal and Shelf Sci., 49: 411-426.

Morris, J. T., Sundareshwar, P. V., Nietch, C. T., Kjerfve, B., Cahoon, D. R. 2002. Responses of coastal wetlands to rising sea level, Ecology, 83, 2869-2877.

Mudd, S. M., Fagherazzi, S., Morris, J.T., Furbish, D. J. 2004. Flow, sedimentation, and biomass production on a vegetated salt marsh in South Carolina: toward a predictive model of marsh morphologic and ecologic evolution, in Fagherazzi, S., Marani, M., Blum, L.K. (Eds.), The Ecogeomorphology of Salt Marshes, Coastal and Estuarine Stud., vol. 59, pp. 165-188, AGU, Washigton, D. C.

Paterson, D. M. 1989. Short-term changes in the erodibility of intertidal cohesive sediments related to the migratory behaviour of epipelic diatoms. Limnol. Oceanogr. 34: 223-234.

Randerson, P. F. 1979. A simulation model of salt-marsh development and plant ecology. In Knights, B. \& Phillips, A. J. (Eds.), Estuarine and Coastal Land Reclamation and Water Storage, pp. 48-67, Farnborough, Saxon House.

Rinaldo, A., Fagherazzi, S., Lanzoni, S., Marani, M. \& Dietrich, W. E. 1999a. Tidal networks 2. Watershed delineation and comparative network morphology. Water Resources Research, 35(12), 3905-3917.

Silvestri, S., Defina, A., Marani, M. 2005. Tidal regime, salinity and salt marsh plant zonation. Estuarine Coastal Shelf Sci. 62: 119-130, doi:10.1016/j.ecss.2004.08.010.

Strogatz, S. 1994. Nonlinear Dynamics and Chaos, Addison Wesley, Reading, MA. 
